\title{
Soil health, soil biology, soilborne diseases and sustainable agriculture: A guide
}

\author{
Graham Stirling, Helen Hayden, Tony Pattison and Marcelle Stirling: CSIRO publishing, \\ Australia, (ISBN 9781486303045), 280 pp
}

Daniel Hüberli ${ }^{1}$ (D)

Received: 9 May 2017 / Accepted: 10 May 2017/Published online: 19 May 2017

(C) Australasian Plant Pathology Society Inc. 2017

This book is written by four scientists that have significant practical research experience in soil biology, soil health and soilborne diseases. The intended audience of this book are Australian farmers, their advisors and agricultural students. As such it is written in a clear and concise style with several cases studies and explanatory boxes that provide more detail on concepts outlined in each chapter. The book's focus is the biological component of soils and how these can be managed to improve soil and plant health in sustainable agriculture in Australia. The first chapter is a basic introduction to soil health, soil biology, and sustainable agriculture and sets the scene for the reader. Chapter 2 provides grounding on the physical, chemical and biological properties of soils, and the role of organic matter in modifying these properties to improve soil health. The micro- and macrobiota that make up the soil food web are outlined in chapter 3, with a focus on beneficial organisms and the ecosystem services they provide including improvement of soil structure, suppression of soilborne disease and plant growth promotion. Some of the most devastating soilborne diseases and nematodes to Australian farmers in a range of agricultural crops are discussed in chapter 4. The concept of disease severity as a dynamic interaction is also introduced. Chapter 5 provides an overview of disease-suppressive organisms and management practices that impact disease suppression. Interestingly, this chapter ends on additive organic and biological products that improve plant health or enhance disease suppression. Chapter 6 brings together concepts from the preceding chapters in a step-by-step guide for the assessment of the soil constraints, modification of soil and crop management practices and monitoring of crops and soil to ascertain whether the practices have achieved the desired outcomes. An extensive table of soil management tactics summarises potential primary and secondary benefits gained from each tactic and their disadvantages. Particularly noteworthy and unique to this book is the practical information provided for improving soil health in different farming systems in Australia including grain (Chapter 7), annual and perennial pastures (Chapter 8), sugarcane (Chapter 9), vegetable (Chapter 10), and perennial horticultural crops (Chapter 11). Chapter 12 succinctly summaries the key soil health messages and the key practices to improve soil health. Finally, current references including websites, books, scientific papers, and extension material that covers the sciences in the book are provided in the references section. This book is an accessible and easy to follow practical guide and provides excellent tools to manage soils in a sustainable way. It demystifies the biological processes of soils in Australian agricultural systems for farmers, advisors and students wanting a basic grounding in disease suppression and soil health.

Daniel Hüberli

daniel.huberli@agric.wa.gov.au

1 Crop Protection, Department of Agriculture and Food, South

Perth, WA, Australia 